\title{
Iterative construction of low-altitude UAV air route network in urban areas: Case planning and assessment
}

\author{
XU Chenchen ${ }^{1,2}$, "LIAO Xiaohan ${ }^{1,3,4}$, YE Huping ${ }^{1}$, YUE Huanyin ${ }^{1,3,4}$ \\ 1. Institute of Geographic Sciences and Natural Resources Research, CAS, State Key Laboratory of \\ Resources and Environmental Information System, Beijing 100101, China; \\ 2. University of Chinese Academy of Sciences, Beijing 100190, China; \\ 3. Institute of UAV Application Research, Tianjin and CAS, Tianjin 301800, China; \\ 4. The Research Center for UAV Applications and Regulation, CAS, Beijing 100101, China
}

\begin{abstract}
With the rapid increase of Unmanned Aircraft Vehicle (UAV) numbers, the contradiction between extensive flight demands and limited low-altitude airspace resources has become increasingly prominent. To ensure the safety and efficiency of low-altitude UAV operations, the low-altitude UAV public air route creatively proposed by the Chinese Academy of Sciences (CAS) and supported by the Civil Aviation Administration of China (CAAC) has been gradually recognized. However, present planning research on UAV low-altitude air route is not enough to explore how to use the ground transportation infrastructure, how to closely combine the surface pattern characteristics, and how to form the mechanism of "network". Based on the solution proposed in the early stage and related researches, this paper further deepens the exploration of the low-altitude public air route network and the implementation of key technologies and steps with an actual case study in Tianjin, China. Firstly, a path-planning environment consisting of favorable spaces, obstacle spaces, and mobile communication spaces for UAV flights was pre-constructed. Subsequently, air routes were planned by using the conflict detection and path re-planning algorithm. Our study also assessed the network by computing the population exposure risk index (PERI) and found that the index value was greatly reduced after the construction of the network, indicating that the network can effectively reduce the operational risk. In this study, a low-altitude UAV air route network in an actual region was constructed using multidisciplinary approaches such as remote sensing, geographic information, aviation, and transportation; it indirectly verified the rationality of the outcomes. This can provide practical solutions to low-altitude traffic problems in urban areas.
\end{abstract}

Keywords: UAV air route network; urban area; iterative construction; remote sensing; geographic information

Received: 2020-03-04 Accepted: 2020-06-02

Foundation: National Key Research and Development Program of China, No.2017YFB0503005; Key Research Program of the Chinese Academy of Sciences, No.ZDRW-KT-2020-2; National Natural Science Foundation of China, No.41971359, No.41771388; Tianjin Intelligent Manufacturing Project: Technology of Intelligent Networking by Autonomous Control UAVs for Observation and Application, No.Tianjin-IMP-2

Author: Xu Chenchen, PhD Candidate, E-mail: xucc.14s@igsnrr.ac.cn

"Corresponding author: Liao Xiaohan (1963-), Professor, specialized in UAV remote sensing and air route planning. E-mail: liaoxh@igsnrr.ac.cn 


\section{Introduction}

Recently, the number of UAVs continues to increase (Alex, 2018), and their applications in urban areas are increasingly diverse (Stolaroff et al., 2018), such as inspecting urban infrastructure (Bahabry et al., 2019), monitoring and planning intelligent urban transportation systems (Menouar et al., 2017), and so on. UAVs are gradually affecting and even changing human life (Floreano et al., 2015). However, UAVs have also brought problems to low-altitude safety in urban areas. In the near future, when UAVs completely occupy low-altitudes, the contrast between flight activities and limited low-altitude airspace resources will become increasingly serious. In order to cope with low-altitude safety issues, some countries and districts currently adopt a general construction of UAV Traffic Management (UTM) systems for UAV regulation (Kopardekar et al., 2016; Bietlot, 2017; Cape et al., 2017; Quan et al., 2020). However, the surficial environment in urban areas is complicated. Due to the lack of geographic information and low-altitude air route support, the current UTM systems cannot ensure the low-altitude operation safety of UAVs. Some countries are exploring technical means to ensure the safe and efficient flight of UAVs. Among them, the technical solution proposed by the Chinese Academy of Sciences (CAS) in 2017 to plan low-altitude air route network based on massive geographic information has been increasingly recognized (Liao et al., 2018; CAAC, 2019). The Civil Aviation Administration of China (CAAC) has also proposed developing low-altitude air route planning and constructing technology (CAAC, 2019) in 2019 by further popularizing and deepening the concept of low-altitude air routes for UAVs. It proposes the future trend of China's development of low-altitude air route networks.

Research on low-altitude air routes at home and abroad focus on the construction of the "road". For example, a Singaporean group proposed the concept of constructing air-route systems over cities in 2014, and then carried out the dynamic planning of the air routes (Lim et al., 2019) flight risk assessment (Tan et al., 2017; Wang et al., 2018; Tan et al., 2019), urban operation, and airspace management of UAVs. Bai et al. (2016) prospected the low-altitude passages for UAVs in urban areas after summarizing the characteristics of UAV activities. Feng et al. utilized technology such as automatic air route construction based on laser point cloud data (2016) and its 3D visualization (2018), and developed an air route traffic management platform (2017). In general, only a few researchers plan the "network" (Schneider et al., 2014; ATMRI, 2017; Salleh et al., 2018). For example, the Air Traffic Management Research Institute built the air route network based on AirMatri, which forms a network by connecting nodes and links without conflicts with urban infrastructure (mainly buildings). Essentially, it is an exhaustive method. Salleh et al. (2018) constructed the air route network over buildings or urban roads, where nodes are set above a building or a road, then are connected to generate a network. None of the above studies make full use of the urban infrastructure and ground transportation facilities. It is especially important to use the well-developed infrastructure in high-altitude urban areas, where the surface is complex and the surface information is dynamically updated.

Our team proposes innovative concepts and the progressive technological path for iteratively constructing the UAV air route network from the perspective of multiple cross-disciplines such as geographic information and remote sensing technology in earlier work (Xu et al., 2020).

This method improves the air route layout dynamically and flexibly and updates the geo- 
graphical elements locally, which is more scientific and reasonable compared with the traditional method of planning civil aviation airlines. This paper seeks to deepen research based on existing theoretical systems and technical paths. Taking the Jing-Jin-Xincheng (JJXC) district of Tianjin in China as a demonstration area, the iterative construction process and technical details of the low-altitude UAV air route network are described in detail and its feasibility is verified by risk assessment. Generating a class I air route network based on ground roads can make full use of the traffic infrastructure and allow close connection with ground transportation. Additionally, avoiding obstacles and verifying the environment map of UAV flights with actual measurement data can ensure flight safety. Compared with previous studies, the iterative construction method proposed in this paper can fully utilize the ground traffic layout and infrastructures, fully combine the characteristics of ground pattern and fully utilize rich surface geographic information to solve the efficient and safe construction of UAV low-altitude air route network. This paper forms a comprehensive solution for managing low-altitude UAV traffic in urban areas by combining the disciplines of aviation, transportation and geography.

\section{Study region and data}

This paper considers JJXC district of Tianjin in China, with convenient transportation and excellent geographical location, as a typical urban area to construct the low-altitude air route network. The area is about $29 \mathrm{~km}^{2}$ in a flat terrain with an average elevation of less than 10 $\mathrm{m}$. Its land use is mainly farmland and rivers, and the proportion of buildings and the population density is relatively low. The building types are mainly low-rise villas and campuses, generally below 70 meters. As a typical urban demonstration area, constructing the low-altitude air route network here can not only reduce the risk of UAV operations to the public, but also reduce the interference of buildings and terrain on the UAV communication.

Data used to construct the low-altitude air route network in this study include orthophoto images of the study area and LiDAR point cloud data along the road. The orthophoto image, captured by a visible light camera mounted on a fixed-wing UAV at a height of $100 \mathrm{~m}$ and a sideline overlap of $80 \%$, has a resolution of $0.05 \mathrm{~m}$ and is used to extract objects sensitive to UAV flights, such as roads and buildings. The laser-point cloud data, collected and processed by the vehicle-mounted lightweight 3D laser moving measurement system, is used to obtain the accurate height of ground objects along the road, such as transmission poles and buildings. To ensure the safety of the UAV communication link, field detection of the communication coverage of the mobile base station is also carried out. A mobile base station in an open area $(117.395427 \mathrm{~W}, 39.546825 \mathrm{~N})$ that was not sheltered by buildings and conformed to the test rules (Al-Hourani et al., 2018) was selected as the signal detection object (Figure 1). The UAV (DJI Phantom 4) and a phone equipped with a signal detection application (speedsky.rnd.huawei.com/), barometer, and GPS were used to detect the electric field intensity along horizontal and vertical paths. The UAV flew at a constant speed of $5 \mathrm{~m} / \mathrm{s}$. The longest distance was $1 \mathrm{~km}$ from the base station and its maximum height was $300 \mathrm{~m}$ according to the investigation by CAAC which indicating that the current cellular network coverage below $300 \mathrm{~m}$ is enough to ensure C2 link security to support UAVs' flights. To ensure the flight safety for UAV, the minimum flying height is set as $30 \mathrm{~m}$ that is higher than the height of most of the surrounding buildings. The horizontal flight paths were at heights of 30 
$\mathrm{m}, 50 \mathrm{~m}, 80 \mathrm{~m}, 100 \mathrm{~m}, 150 \mathrm{~m}, 200 \mathrm{~m}, 250 \mathrm{~m}$ and $300 \mathrm{~m}$; the vertical flight path, from 10 to $300 \mathrm{~m}$, was located $1 \mathrm{~km}$ from the base station. The Reference Signal Receiving Power (RSRP)-a key parameter of indicating signal strength-was sampled and recorded in a frequency of $1 \mathrm{~Hz}$ to represent the strength of the wireless signal.

Combined with the construction process of the air route network (Xu et al., 2020), the necessary and optional positive or negative constraints for each level of the air route network construction are explored to form the minimum general element set (Table 1). Based on the high-resolution UAV remote sensing image, this paper extracted each constraint largely affecting UAV flights (buildings, roads, transmission poles, street lamps, etc.), and the results are shown in Figure 1.

Table 1 The minimum general element set for the iterative construction process of regional air route network

\begin{tabular}{|c|c|c|c|c|}
\hline Step & $\begin{array}{c}\text { Key tech- } \\
\text { nology }\end{array}$ & Required elements & $\begin{array}{l}\text { Optional } \\
\text { elements }\end{array}$ & Required data processing \\
\hline I & $\begin{array}{l}\text { Hierarchi- } \\
\text { cal plan- } \\
\text { ning }\end{array}$ & $\begin{array}{l}\text { Road network: } \\
\text { urban expressway, } \\
\text { urban main road, } \\
\text { community or } \\
\text { campus internal } \\
\text { trunk road } \\
\text { Mobile base } \\
\text { station. }\end{array}$ & $\begin{array}{l}\text { Roads around } \\
\text { buildings within } \\
\text { a community or } \\
\text { campus. }\end{array}$ & $\begin{array}{l}\text { Road network: extract the road area and its center } \\
\text { line and measure the road width. The road is } \\
\text { stored in the form of shapefile. A road is a record } \\
\text { composed of the coordinate values of feature } \\
\text { points. } \\
\text { Mobile base station: analyze the communication } \\
\text { coverage limit and determine the regional route } \\
\text { height limit accordingly. }\end{array}$ \\
\hline II & $\begin{array}{l}\text { Utilizing } \\
\text { positive } \\
\text { constraints }\end{array}$ & $\begin{array}{l}\text { None. } \\
\text { The positive con- } \\
\text { straint element is } \\
\text { only auxiliary but } \\
\text { not required. }\end{array}$ & $\begin{array}{l}\text { Urban green belt, } \\
\text { isolation belt, } \\
\text { grassland, street } \\
\text { trees, parks, and } \\
\text { other green areas; } \\
\text { rivers, large areas } \\
\text { of waters, } \\
\text { ditches, and other } \\
\text { water sources. }\end{array}$ & $\begin{array}{l}\text { Green space: the relative position with the road } \\
\text { determines the translation direction and transla- } \\
\text { tion distance, and thus the direction and transla- } \\
\text { tion distance matrices. } \\
\text { Water area: the relative position with the road } \\
\text { determines the translation direction and transla- } \\
\text { tion distance, and thus the direction and transla- } \\
\text { tion distance matrices. }\end{array}$ \\
\hline III & $\begin{array}{l}\text { Avoiding } \\
\text { negative } \\
\text { constraints }\end{array}$ & $\begin{array}{l}\text { General obstacles: } \\
\text { buildings, mobile } \\
\text { base station tower } \\
\text { poles, street lamps, } \\
\text { power lines (poles), } \\
\text { etc. }\end{array}$ & $\begin{array}{l}\text { Other obstacles, } \\
\text { such as terrain in } \\
\text { constructing the } \\
\text { route in moun- } \\
\text { tainous areas. }\end{array}$ & $\begin{array}{l}\text { Mobile base station: the clearance boundary } \\
\text { modeling of the tower pole is used to build an } \\
\text { "obstacle" environment, and the communication } \\
\text { coverage is modeled to analyze the spatial signal } \\
\text { distribution. } \\
\text { Other ground objects: to construct a mathematical } \\
\text { model of clearance boundary. }\end{array}$ \\
\hline
\end{tabular}

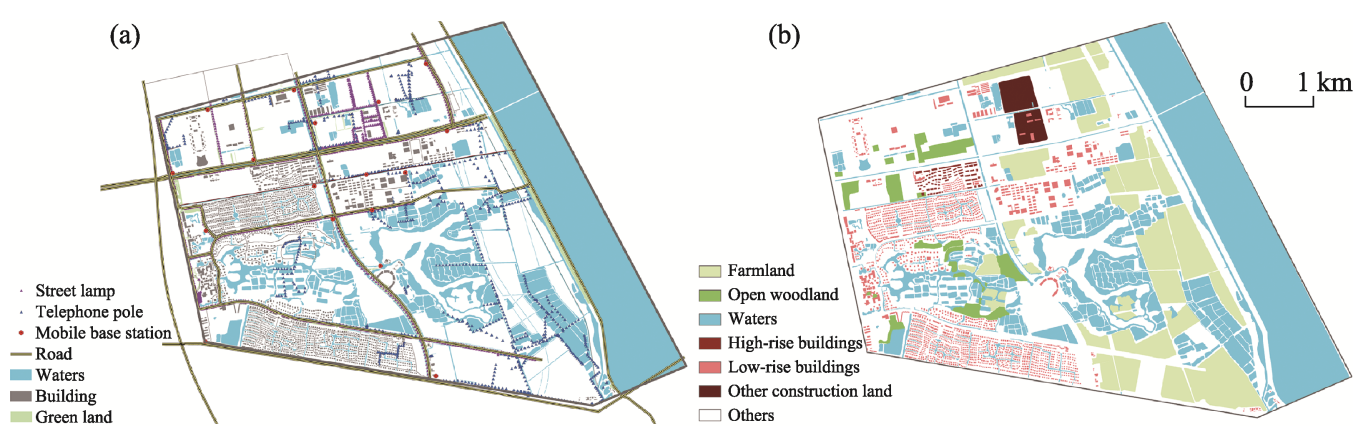

Figure 1 Ground objects distribution (a) and land use classification (b) in JJXC district

\section{Methods and implementation}

Based on UAV remote sensing images and LiDAR point cloud data, this paper extracts con- 
straints on the air routes and constructs the planning environment, including the favorable space, obstacle space and communication space, etc., by mathematical modelling combined with the measured data and gridding technology. We then iteratively construct the low-altitude air route network by utilizing positive constraints, avoiding negative constraints, and optimizing the path. Specific methods and implementation are shown as Figure 2.

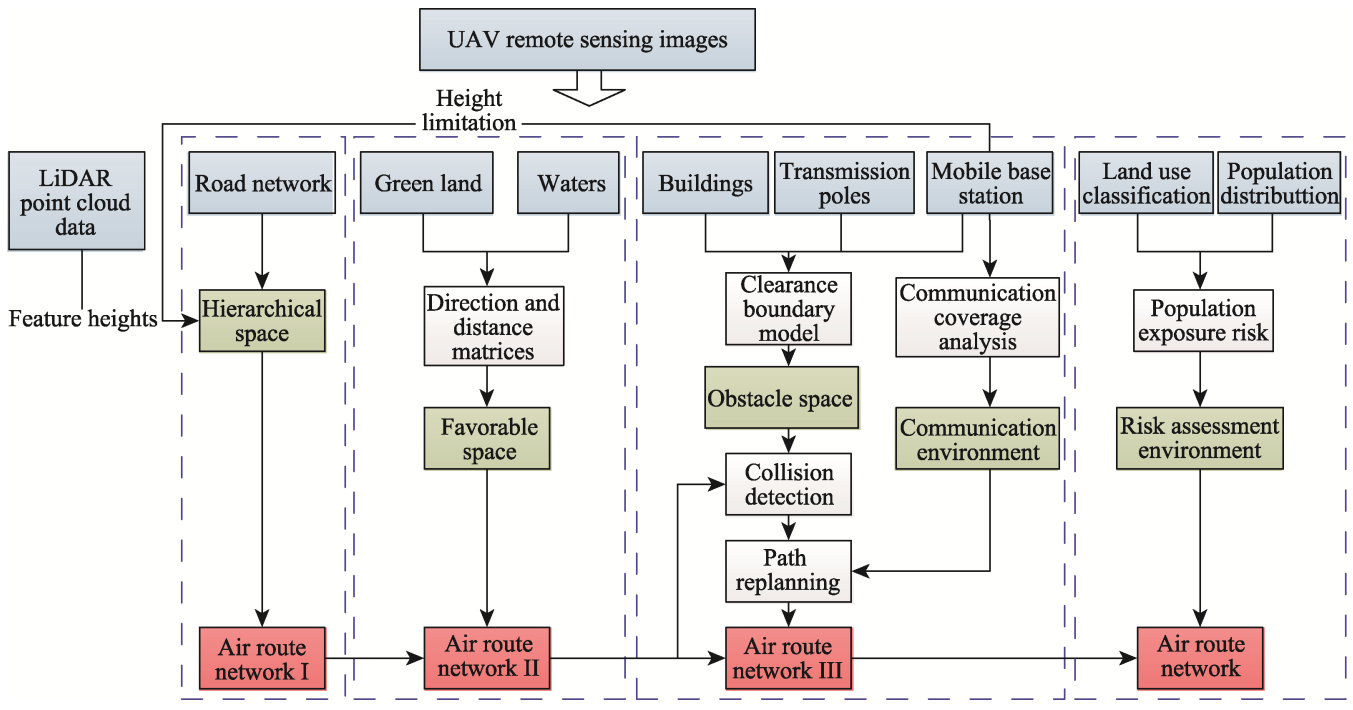

Figure 2 Roadmap of iteratively constructing the multi-level air route network in urban areas

\subsection{Construction of path planning environment}

In order to ensure UAV flying safety, it is necessary to pre-construct the low-altitude environment, which includes defining the path planning space, modelling flight constraints, and mapping the physical obstacle space into the gridding space.

(1) Path planning space

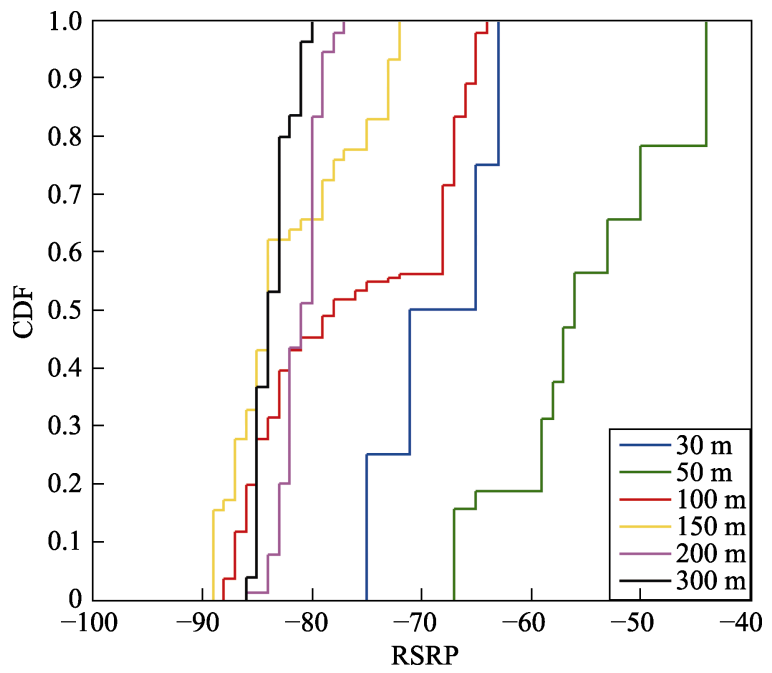

Figure 3 The Cumulative Distribution Function (CDF) for RSRP index of the single base station
The safety of UAV flights are greatly affected by communication links; mobile communication is the foundation of networked UAVs (Lin et al., 2018). The upper height limit of the path planning space is thus determined by signal coverage. Field test results of the communication coverage (Figure 3) show that the RSRP of single base stations decreases with the increase in height. The signal intensity from 30 to $300 \mathrm{~m}$ is between -90 and $-60 \mathrm{dBm}$ and becomes stable between -90 and $-80 \mathrm{dBm}$ at $300 \mathrm{~m}$ above the ground. Therefore, the maximum height of the planned area is set to $300 \mathrm{~m}$, which is 
consistent with the networking performance test results published by the CAAC for low-altitude cellular mobile network UAVs (CAAC, 2018).

(2) Obstacle and communication space for UAV operation

The geographical elements restricting the low-altitude UAV flight mainly include physical obstacles, such as buildings, transmission poles, mountains, and virtual obstacle spaces such as weak signal zones, electromagnetic danger zones and extreme weather zones. However, JJXC is characterized by flat terrain, non-significant climate change, and is mainly dominated by residential areas without electromagnetic danger zones. Therefore, this study only models and analyzes the distribution of mobile communications, buildings, and transmission poles.

The buildings in the study area are mainly single-family villas and middle and high-rise residential buildings, with relatively regular shapes. To simplify the calculation, the smallest external cuboid is used to represent the high-rise buildings. Transmission poles, street lamps and mobile tower poles are represented by a grid in the calculated environment map due to their small floor space. According to statistics, a total of 17 mobile communication base stations are evenly distributed around the residential areas and schools in the concerned area. The single base station channel model is constructed as follows by using the cellular network signal path loss formula published by the Third Generation Partnership Project (3GPP) (3GPP, 2017) combined with the actual measurement data (RSRP index value) and empirical parameters.

$$
\begin{gathered}
P L_{U A V}(d, \theta)=\alpha \times 10 \times \lg (d)+\beta+X_{\delta} \\
X_{\delta} \sim \mathcal{N}(0, \delta) \\
P L_{U A V}=P_{T}+G(\omega, \varnothing)-R S R P
\end{gathered}
$$

where $d$ is the spatial distance from the measuring point to the base station, and $\theta$ is the antenna downdip angle, set as $10^{\circ}$ according to the actual survey; $\alpha$ is the path loss index, and $\beta$ is the cut-off point at $d=1 \mathrm{~m} . X$ is a random number following a normal distribution, and $\delta$ is the standard deviation. The values of $\alpha, \beta$, and $\delta$ are respectively set to 2.0/35.3/3.4 (at 80 $\mathrm{m}$ ), 2.1/32.8/4.4 (at $50 \mathrm{~m}$ ) and 2.5/20.4/5.2 (at $30 \mathrm{~m}$ ) (Amorim et al., 2017). $P_{T}$ is the average transmitting power of each unit-symbol mobile base station, whose value is set as 43 $\mathrm{dBm} . G$ is the antenna gain, set as 18 (Zhu et al., 2015) that changes with the azimuth angle $\omega$ and the inclination angle $\varnothing$ between UAV and antenna. Formula (3) is used to convert the actual measured RSRP index value into the path loss sample $P L_{U A V}$.

According to the signal grading standard of China Mobile-LTE field test specification (China Mobile, 2012), single base station signals are divided into four levels: excellent $(R S R P>-85 \mathrm{dBm})$; good $(-95 \mathrm{dBm}<R S R P<-85 \mathrm{dBm})$; midpoint $(-105 \mathrm{dBm}<R S R P<$ $-95 \mathrm{dBm})$; others $(R S R P<-105 \mathrm{dBm})$. Delaunay triangulation algorithm was used to extract and fit the boundary of discrete points, and the signal distribution at all levels was obtained as shown in Figure 4. The signal classification distribution in the study area is shown in Figure 5.

The minimum gridding cell was set to $1 \mathrm{~m} \times 1 \mathrm{~m}$; the distribution of mobile communication signals at different elevations and buildings and other ground objects were transformed into grid sets to construct the multi-attribute gridding environment map. The raster attribute corresponding to the obstacle was the height value; the raster attribute corresponding to the 

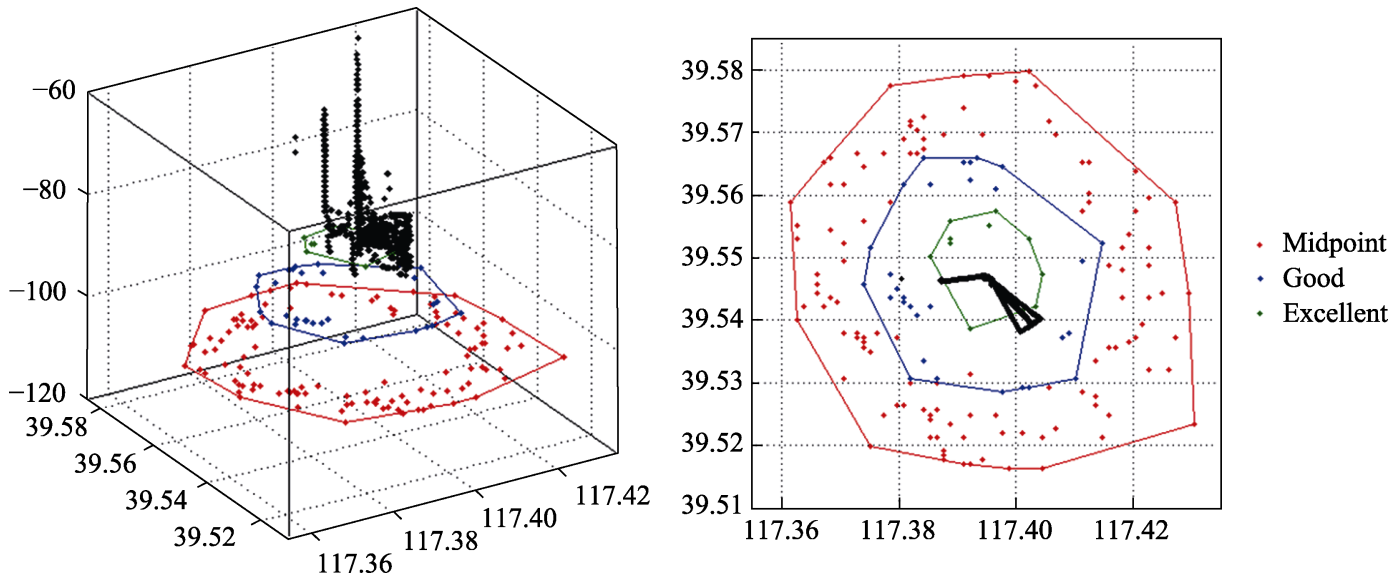

Figure 4 Schematic diagram of single base station signal modeling at 120-m height

communication was the classification standard.

\subsection{Iterative construction of air route network}

(1) Class I air route network constructed by hierarchical classification

Urban road network planning has been developed for several decades, which divides urban roads into expressway, main and secondary trunk roads, and branch networks. Among them, expressway connects with urban entrances and exits and

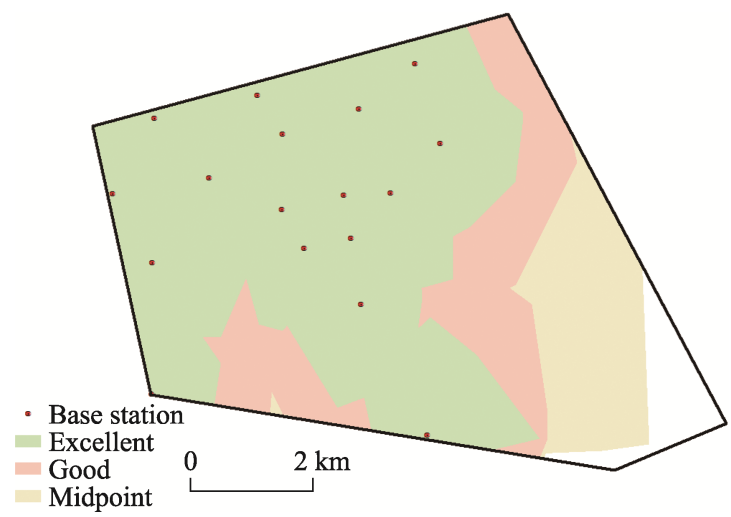

Figure 5 Schematic diagram of regional signal distribution of base stations at $120-\mathrm{m}$ height municipal high-grade highways to undertake inter-city traffic. The primary and secondary trunk roads are the evaluation components of the urban road network, and are the traffic arteries connecting the main districts of the city. Branch network is the connecting line between sub-trunk road and the inner road of residential area and other units, which is responsible for the internal traffic of units (Wang and Chen, 2017).

Referring to the planning experience of urban road network, and in order to efficiently utilize the low-altitude airspace in the urban area, and to orderly and safely regulate UAV operations, this paper classifies the air route into three categories according to its height stratification and function characteristics (Table 2). Type 1 connects urban areas with the outside area, corresponding to the functions of urban expressway; type 2 refers to the main traffic routes inside the urban areas, corresponding to the parimary and secondary main routes in the city; and type 3 is the internal air route of community units in the urban area, such as the internal air route in residential communities or campuses, corresponding to the branch network. Each type of air route is at a different height, so its geographical constraints are different. The height of each air route type is determined by the function, regional ground object distribution and safe height interval between adjacent air routes (Xu et al., 
2020). On this basis, the ground network in vector form with a certain width will be vertically elevated, and will be highly classified according to the flight level of each type of air route, so as to form the class I air route network at multiple flight levels.

Table 2 Air route classification and relative attributes in JJXC district (Xu et al., 2020)

\begin{tabular}{|c|c|c|c|c|c|}
\hline Types & Function & Constraints & $\begin{array}{l}\text { Height } \\
(\mathrm{m})\end{array}$ & $\begin{array}{l}\text { Minimum } \\
\text { height }(\mathrm{m})\end{array}$ & Platform \\
\hline 1 & $\begin{array}{l}\text { Connecting urban areas with } \\
\text { the outside area }\end{array}$ & $\begin{array}{l}\text { Higher than most of ground } \\
\text { objects in urban area }\end{array}$ & $70-300$ & 70 & $\begin{array}{l}\text { Fixed wing/multi- } \\
\text { rotor UAV }\end{array}$ \\
\hline 2 & $\begin{array}{l}\text { Main traffic routes inside the } \\
\text { urban areas }\end{array}$ & $\begin{array}{l}\text { Higher than lamps, trees, } \\
\text { and buildings along roads }\end{array}$ & $50-70$ & 50 & Multi-rotor UAV \\
\hline 3 & $\begin{array}{l}\text { Internal air route of community } \\
\text { units in urban area }\end{array}$ & None & $15-50$ & 30 & Multi-rotor UAV \\
\hline
\end{tabular}

(2) Class II air route network constructed by utilizing favorable space

Based on the results of the class I air route, the class II route network is constructed by making full use of the favorable geographical space available for UAV's low-altitude flights. In this paper, the space over green land and water area along roads in JJXC district are utilized and are taken into constructing progress of the class II air route network.

Firstly, a direction matrix is constructed according to the positional relationship between the green space, water area and road, based on the ground object distribution (Figure 2). In this matrix, +1 represents the north direction, -1 represents south, +2 represents east and -2 represents west. A distance matrix is then constructed based on the actual distance between the green land, water area and road. The actual distance between the road centerline in this region and the green land and water area is obtained by actual investigations. The distance needed to extend by the class I air route is shown in Figure 6. It also stipulates that the north-south class I air route extends eastward, and the east-west class I air route extends northward.

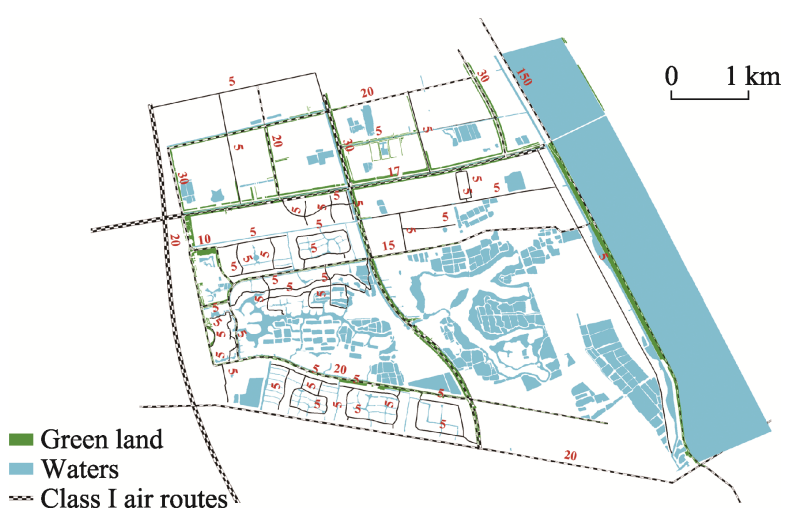

Figure 6 Moving distances for each class I air route obtained from actual investigations

Secondly, the class I air route is simplified as a network composed of the road centerline. Then the centerline is divided into several straight segments in the abrupt slope points by detecting its slope change. Thus, the class I air route consists of a series of ordered points. Based on this, a new path is formed by moving the straight segments along the normal line according to the direction and distance matrices by the edge expansion algorithm. Based on the endpoint coordinates, the direction and distance matrices, the new path is calculated by the following formulas:

$$
\begin{gathered}
\theta_{1}=\frac{P_{j}(i+1,2)-P_{j}(i, 2)}{P_{j}(i+1,1)-P_{j}(i, 1)} \\
\theta_{2}=\frac{y_{i}-P_{j}(i, 2)}{x_{i}-P_{j}(i, 1)}
\end{gathered}
$$




$$
\theta_{3}=\frac{y_{i+1}-P_{j}(i+1,2)}{x_{i+1}-P_{j}(i+1,1)}
$$

s.t. $\left(x_{i}, y_{i}, x_{i+1,} y_{\mathrm{i}+1}\right)=\left\{\begin{array}{l}\theta_{1}^{*} \theta_{2}=-1 \\ \theta_{1}^{*} \theta_{3}=-1 \\ \left(y_{\mathrm{i}}-P_{j}(i, 2)\right)^{2}+\left(x_{i}-P_{j}(i, 1)\right)^{2}=\text { Distance }_{j}{ }^{2} \\ \left(y_{\mathrm{i}+1}-P_{j}(i+1,2)\right)^{2}+\left(x_{i+1}-P_{j}(i+1,1)\right)^{2}=\text { Distance }_{j}{ }^{2},{\text { if } \text { Direction }_{j}<0 .} \text {. } \\ y_{i}<P_{j}(i, 2) \\ y_{i+1}<P_{j}(i+1,2)\end{array}\right.$

$$
\text { s.t. }\left(x_{i}, y_{i,} x_{i+1,} y_{\mathrm{i}+1}\right)=\left\{\begin{array}{l}
\theta_{1}^{*} \theta_{2}=-1 \\
\theta_{1}^{*} \theta_{3}=-1 \\
\left(y_{\mathrm{i}}-P_{j}(i, 2)\right)^{2}+\left(x_{i}-P_{j}(i, 1)\right)^{2}=\text { Distance }_{j}^{2} \\
\left(y_{\mathrm{i}+1}-P_{j}(i+1,2)\right)^{2}+\left(x_{i+1}-P_{j}(i+1,1)\right)^{2}=\text { Distance }_{j}^{2} \\
y_{i}>P_{j}(i, 2) \\
y_{i+1}>P_{j}(i+1,2)
\end{array} \text { if } \text { Direction }_{j}>0 .\right.
$$

where $\left(x_{i}, y_{i}\right),\left(x_{i+1}, y_{i+1}\right)$ is the ordered point coordinates of the moved path; $\theta_{1} \times \theta_{2}=-1$ ensures that the movement is along the normal line; $\left(P_{j}(i, 1), P_{j}(i, 2)\right),\left(P_{j}(i+1,1), P_{j}(i+\right.$ 1,2)) is the ordered coordinate of the $j$ th path, which is constituted by the lines between adjacent points. Distance $_{j}$ is the moving distance of the $j$ th path, and Direction $_{j}$ is the moving direction of the $j$ th path.

Finally, the performance of the UAV requires a continuous curvature of air routes to ensure flight safety. The paths are smoothed by cubic non-uniform B-spline technology (Duan et al., 2018), the core of which solves the control points of the B-spline curve according to the known route end points to be smoothed. The process is as follows: 1) parameterizing the

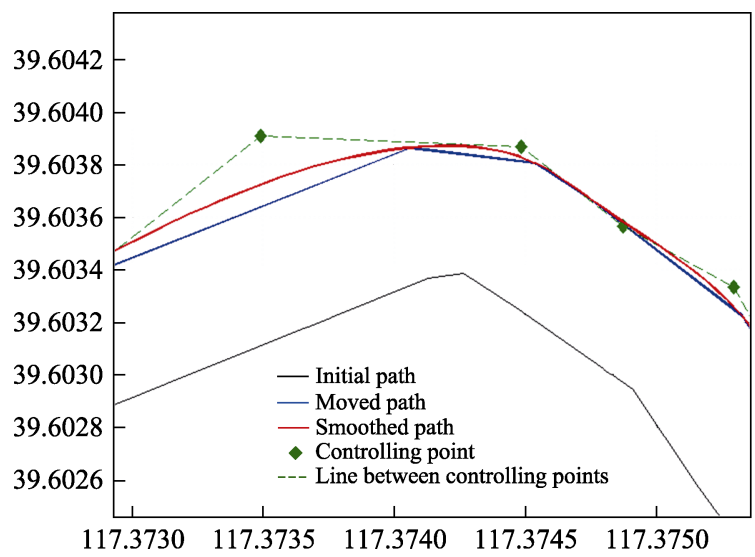

Figure 7 Diagram of comparison among the initial path, structed by avoiding obstacle space moved path and smoothed path chord length and constructing the non-uniform node vector according to the distribution of the type value points; 2) constructing the non-uniform B-spline base; 3) constructing the coefficient matrix to calculate the control point in reverse; 4) calculating the control point in reverse; and 5) interpolating to get the spline curve, i.e., the smooth path. The smooth optimization effect of air route segments is shown in Figure 7.

(3) Class III air route network conObstacles (buildings and transmission 
poles) are not considered when constructing the class II air route network, and the UAV may pass through the obstacles during flights, thus causing severe damage. Additionally, communication security is also an important prerequisite for safe UAV flight and supervision. Therefore, UAV obstacle avoidance and communication security are considered in this part.

Based on gridding maps at different heights, hierarchical planning was carried out, i.e., the type 1 air route network was planned within the $80-300 \mathrm{~m}$ height range, the type 2 air route network within the 50-80 m range and the type 3 air route network within the $30-50 \mathrm{~m}$ range. Other parameters for each type of air route network are set as follows: the minimum height is 80,50 , and $30 \mathrm{~m}$, respectively; both the width and safe buffer distance of the air route are $1 \mathrm{~m}$. To efficiently plan the path, the $2 \mathrm{D}$ flight path planning in the plane at the specific height was undertaken, along with the 3D path planning based on the terrain and UAV pitch performance (Xu et al., 2019a). The route construction process is presented in Figure 8.

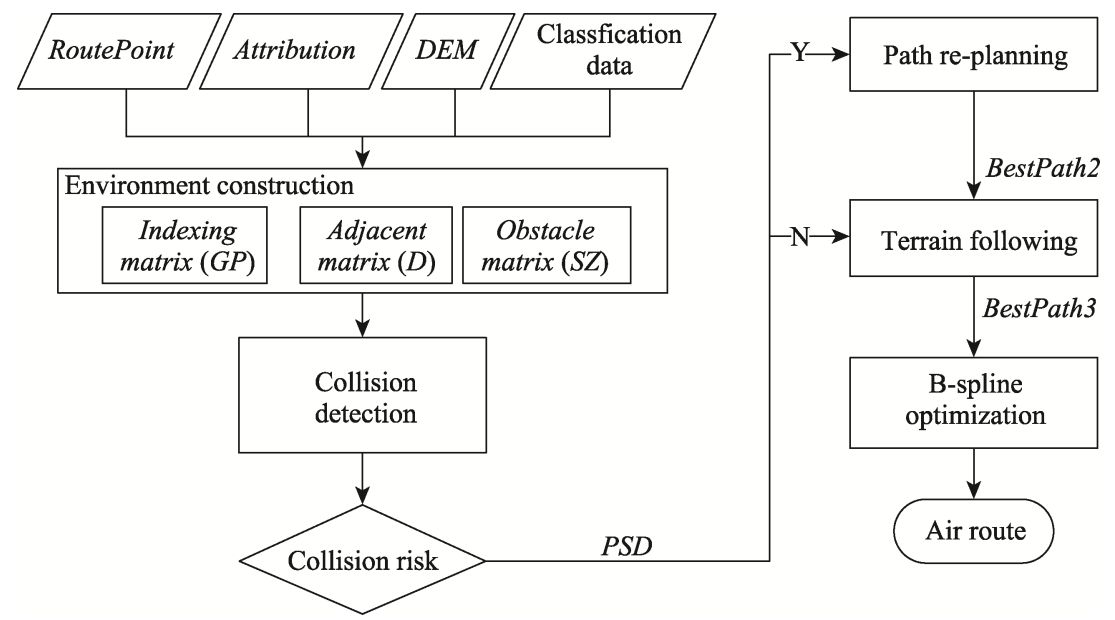

Figure 8 Flowchart of the main process of constructing the class III air route network (DEM: Digital Elevation Model)

\section{1) Collision detection}

The calculated index space $(G P)$ and adjacent matrix $(D)$ was constructed based on the gridding map; conflicts between air routes and obstacles were detected to obtain the start and end point coordinates $(P S D)$ of the air routes to be re-planned.

$G P$ is mapped by the actual space according to the longitude and latitude trend and the minimum cell. $D$ represents the relationship between adjacent nodes, where all the grid properties of buildings, street lamps, transmission and tower poles are 1, implying that the cell is not adjacent to other cells. The collision is manifested as the air route point located in the obstacle cell, represented as an abrupt point, and constitutes the start and end point coordinate matrix $P S D$ of the re-planned segment.

2) Re-planning of air route

After inputting $P S D$, the 2D path is re-planned based on the Improved Ant Colony Optimization (IACO) algorithm by considering distance and communication strength as objective functions. The re-planned path avoids all obstacles on the premise of ensuring optimal communication quality and the shortest distance. 
In the IACO algorithm, parameters are set as follows: the pheromone factor $\alpha$ is 2 , heuristic factor score $\beta$ is 5, increased intensity $Q$ of pheromone is 100,200 rounds of foraging activities and twice as many ants as the number of cells in each round is set to search for the optimal path. The objective function is:

$$
F=-W_{1} \times P+W_{2} \times D
$$

where $P$ is the communication quality, $D$ is the route distance, and $W_{1}$ and $W_{2}$ are their weights. Considering that the communication signal coverage in most of the study area is good (Figure 5), the shortest distance is taken as the main target; thus $W_{1}$ and $W_{2}$ are 0.8 and 0.2 , respectively. The ant colony algorithm (ACO) is classic, and this study carries out the path optimization based on the previous work (Xu et al., 2019b). Therefore, the IACO is not described in detail.

\section{3) Terrain following}

The terrain following planning is carried out according to the terrain and UAV pitching performance, and the path optimization is then carried out to obtain the class III air route network (Figure 9). Terrain following planning has also been described in detail in the preliminary work (Xu et al., 2019a), and is not discussed here.

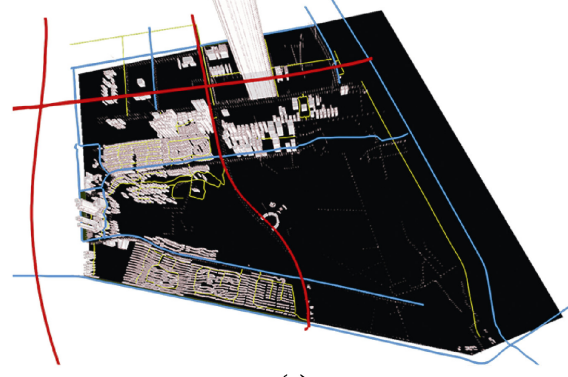

(a)

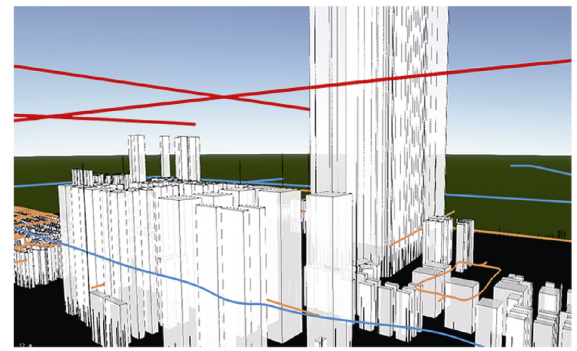

(b)

Figure 9 Low-altitude UAV air route network and its local enlarged map in the JJXC district (Red lines: type 1 air routes; blue lines: type 2 air routes; yellow lines: type 3 air routes)

(4) Network capability assessment

The network capability highlights the structural characteristics of the air route network. It is measured by calculating the cross-conflict coefficient as follows, reflecting the conflict risk of the UAV at the intersection.

$$
P=\frac{2 F_{1} F_{2}}{V} \times X \times \sec \frac{\alpha}{2}
$$

where $P$ is the cross-conflict coefficient; $F_{1}$ and $F_{2}$ are the corresponding flow for each air route at the intersection point and are set as 10 aircrafts per hour; $v$ is the average speed of the $\mathrm{UAV}$, set as $11 \mathrm{~m} / \mathrm{s} ; X$ is the lateral interval under the control, set as $30 \mathrm{~m} ; \alpha$ is the angle between different routes at the intersection point. The greater the coefficient value, the greater the conflict risk between UAVs.

\subsection{Risk assessment index}

Public safety is the primary concern of UAV operations at low altitudes. Therefore, this study assesses the air route network by calculating the population exposure risk index 
(PERI). Firstly, the sheltering factor value for each type of land for UAV impact is based on the land use classification data and land classification criteria (as presented in Table 3) (Primatesta et al., 2018). Secondly, a single-person exposure model in the risk of a UAV collision is constructed to calculate the single-person risk, and the population density data and sheltering factor value are combined to calculate the regional population exposure risk.

$$
\begin{gathered}
R_{p}=A_{\text {exp }} \times D_{p} \times P_{\text {single }} \times P_{\text {Risk }} \\
A_{\text {exp }}=\pi \times\left(r_{p}+r_{U A V}\right)^{2} * \sin (\gamma)+2 \times\left(r_{p}+r_{U A V}\right) \times\left(h_{p}+r_{U A V}\right) \times \cos (\gamma) \\
P_{\text {single }}=\frac{1-k}{1-2 * k+\sqrt{\frac{\alpha}{\beta} *\left[\frac{\beta}{E}\right]^{\frac{3}{P_{s}}}}} \\
k=\min \left[1,\left[\frac{\beta}{E}\right]^{\frac{3}{P_{s}}}\right] ! \\
E=\frac{1}{2} * m^{*} v^{2}
\end{gathered}
$$

where $A_{\text {exp }}$ refers to the risk of a single person being exposed to a collision; $D_{p}$ is population density per $1 \mathrm{~km}^{2} ; P_{\text {single }}$ refers to the injury probability of a single person in a collision, and $P_{\text {Risk }}$ is the probability of collision. To calculate $A_{\text {exp }}$, a single person is abstracted as a cylinder with radius $r_{p}$ and height $h_{p} . r_{U A V}$ is the semi-wingspan, $\gamma$ is the glide angle of the UAV, and $P_{s}$ is the sheltering factor (Table 3 ). $E$ is the kinetic energy of the UAV in the collision, while $m$ and $v$ are the mass and speed of the UAV, respectively. $\alpha$ is the impact energy required when $P_{S}$ is equal to 6 and the probability of injury is $50 \%$, and $\beta$ is the impact energy required when $P_{s}$ is equal to 0 and the probability of injury is 0 .

According to the single-person exposure model proposed by Primatesta et al. (2018) a single person is abstracted and modelled as a cylinder with a radius of $0.2 \mathrm{~m}\left(r_{p}\right)$ and a height of $2 \mathrm{~m}\left(h_{p}\right)$. It assumes that a multi-rotor UAV with a weight of $1.5 \mathrm{~kg}(\mathrm{~m})$ and a wingspan of $0.35 \mathrm{~m}\left(r_{U A V}\right)$ hits the crowd at $10 \mathrm{~m} / \mathrm{s}(v)$ and a $45^{\circ}$ glide angle $(\gamma)$ at the premium of a $2.16 \%$ probability $\left(P_{\text {Risk }}\right)$ of UAV collision risk per hour.

The preliminary results of the population exposure risk value in the study area are shown in Figure 10. It indicates that the distribution of the population risk value is the same as that of the population distribution in most areas. However, the risk value of some densely populated areas is not high. This is presumably because buildings offset damage by UAV strikes to the public to some extent by combining with the distribution of ground objects.

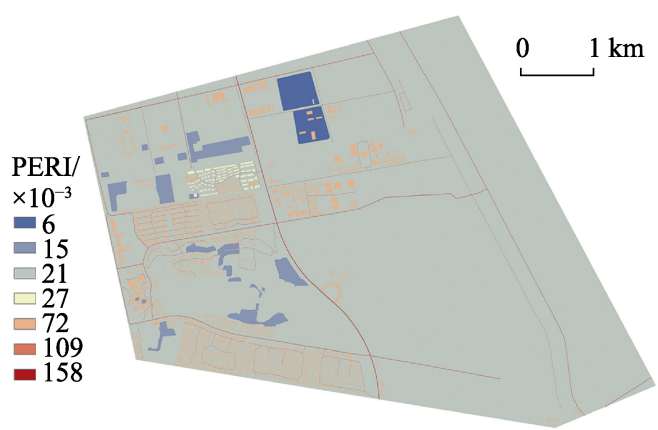

Figure 10 Population exposure risk distribution of UAV operation in the study area 
Table 3 Sheltering factor for each type of land use

\begin{tabular}{|c|c|c|}
\hline Code & Type & Sheltering factor \\
\hline 12 & Farmland & 0 \\
\hline 23 & Open woodland (canopy density $10 \%-30 \%$ ) & 2.5 \\
\hline 41 & Waters & 0 \\
\hline 51 & High-rise buildings & 7.5 \\
\hline 52 & Low-rise buildings & 5 \\
\hline 53 & $\begin{array}{l}\text { Other construction land: factories and mines, large industrial zones, oil fields, salt } \\
\text { fields, quarries and other patches of land; traffic roads, airports, and special areas }\end{array}$ & 10 \\
\hline 61 & Others, including of unexploited land (e.g., deserts, salt flats, marshes) & 0 \\
\hline
\end{tabular}

\section{Results and analysis}

\subsection{Air route network}

Figure 11 shows the air route network from class I to class III. The air route network covers most of the built-up areas and is evenly distributed around the buildings to meet UAV traffic requirements. Being parallel to roads and at a certain distance from roads makes it easy for the UAV to utilize the road traffic infrastructure. The cross-conflict coefficient of the network is 177 , indicating a lower collision risk between UAVs when they operate along the air route network than operate along the network constructed by method from CAAC (CAAC, 2009). Moreover, network cross conflicts only exist between the same type of air route. For different types of air routes, the UAV flies at different height levels and realizes transfer by airspace connection to eliminate collision risk among aircrafts. This indicates that the hierarchical planning can effectively reduce the risk of air route operation.

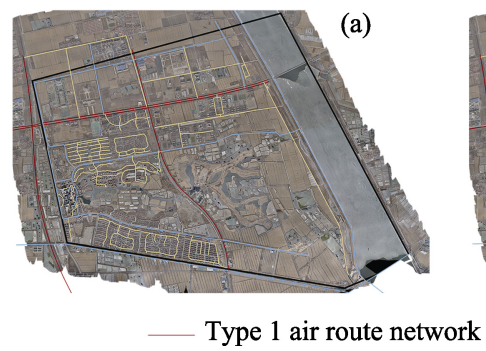

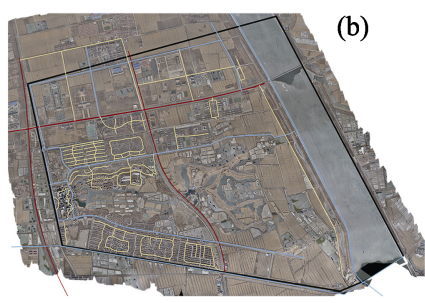

Type 2 air route network

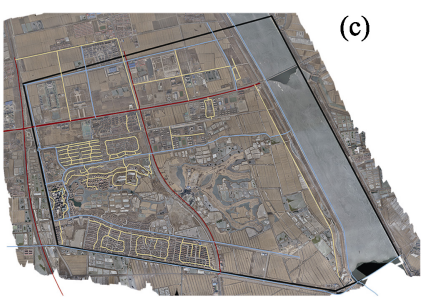

Type 3 air route network

Figure 11 Maps showing each iterative air route network (a. class I air route network; b. class II air route network; c. class III air route network)

There is no obvious difference among each level of air route network in the global figure (Figure 11) due to the scale problem. Figure 12, which is the enlarged local map for class I to class III air route networks, is thus presented. It shows that the class I air route is above the road, and the class II air route is offset to the north and west by a migration distance from class I, which aims to reduce the secondary damage to the road pedestrian or vehicle due to UAV failures. However, some segments of the class II air route collide with buildings after the deviation (blue line in Figure 12), thus leading to a collision risk. Therefore, the collision segment is re-planned by the IACO algorithm and optimized and the class III air route (yellow line in Figure 12) is obtained, which avoids both secondary damages over the road and building conflicts. 


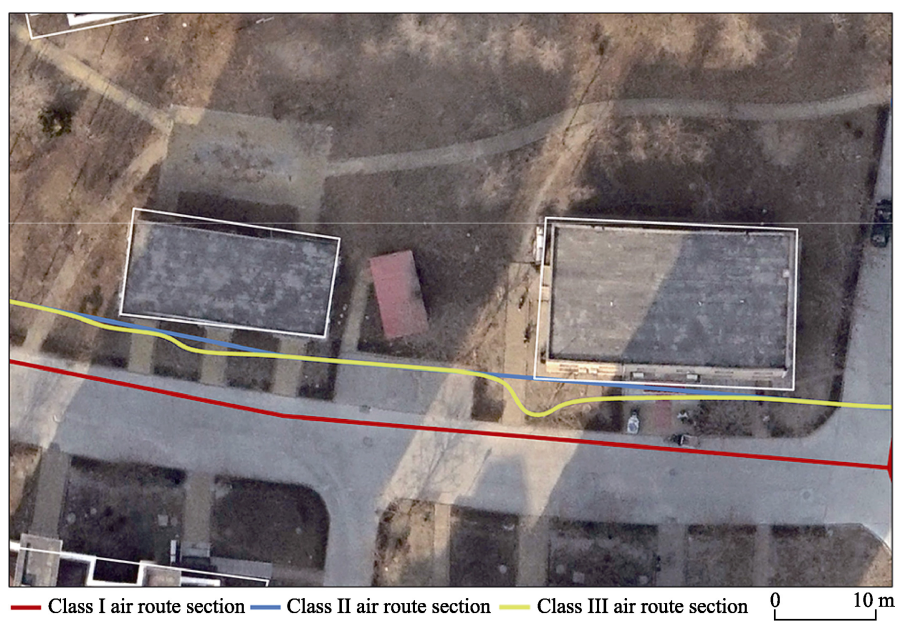

Figure 12 Enlarged local map for class I-III air routes

\subsection{Risk assessment}

Table 4 shows the PERI value for each class air route network. It shows that with successive iterations of the air route network, the risk of exposing the population to the air route network gradually decreases and tends to stabilize with full use of the favorable space and avoiding obstacle spaces.

Table 4 Comparison of the population exposure risk for iterative UAV low-altitude air route network

\begin{tabular}{|c|c|c|c|c|c|c|}
\hline \multirow{3}{*}{ Type } & \multicolumn{6}{|c|}{ Population exposure risk index (PERI) } \\
\hline & Average & Variance & Average & Variance & Average & Variance \\
\hline & \multicolumn{2}{|c|}{ Type 1} & \multicolumn{2}{|c|}{ Type 2} & \multicolumn{2}{|c|}{ Type 3} \\
\hline Class I & 62.42 & 62.92 & 158 & 0 & 117.47 & 62.14 \\
\hline Class II & 21.75 & 9.05 & 25.98 & 15.35 & 23.92 & 17.88 \\
\hline Class III & 21.74 & 8.89 & 25.06 & 14.05 & 25.37 & 22.17 \\
\hline
\end{tabular}

The risk was greatly reduced from class I to class II air route network in particular; thus, UAV operation safety is guaranteed. We found that the class I air route network is located directly above roads with many pedestrians, vehicles, and populations without shelter. Secondary damage can easily on the ground once the UAV fails. Class II construction is carried out over green land and water area along roads, which not only avoids the secondary ground damage caused by UAV failure but also provides services for UAV operation in terms of making ground road facilities nearby available for use.

The difference in the risk between class II and III is not obvious; sometimes, the value of the class III risk is greater than that of class II, such as for the type 3 air route network (17.88 and 22.17). As more than $80 \%$ of buildings in the study area are lower than $30 \mathrm{~m}$, which is the minimum height of the type 3 air route network, the collision probability is very low. Even if re-planning can significantly reduce the risk, there is no obvious risk reduction except from the viewpoint of overall risk due to the low probability of collision. Additionally, smooth optimization is carried out to make the air route conform to the kinetic characteristics of the UAV for the class III air route network. In the process of smoothing, it is inevita- 
ble that the air route would cross part of a road, thus leading to increased risk. Therefore, the population exposure risk of the class III air route network is slightly higher than that of class II.

However, from the perspective of overall risk, the class III air route network avoids the collision and flight dynamic risks and is thus more optimal than class II.

Additionally, the path from the UAV integrated verification field to the Hyatt hotel was taken as an example to assess the air route network. A method proposed by Salleh et al.

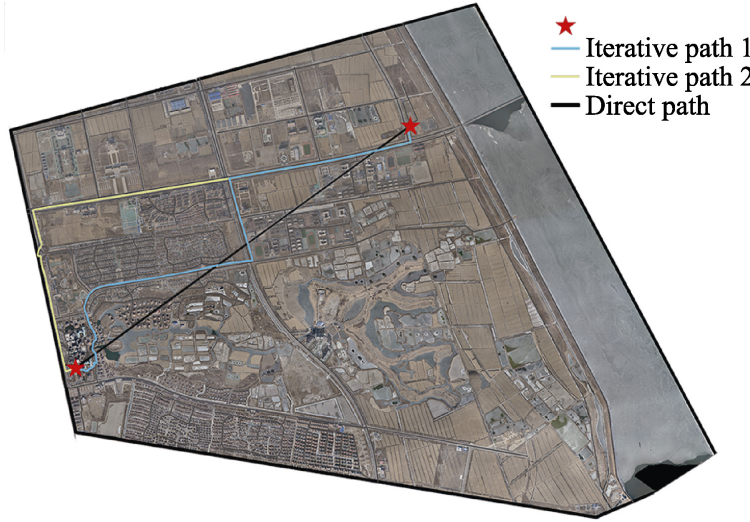

Figure 13 Direct and iterative paths for population risk comparison (2018) considers the building roof as a landing point and connects UAV landing points by a straight line to construct the air route network. It is then compared with two optimal paths from iterative outcomes for the comparative analysis (Figure 13). According to statistics, the average risk of the direct route was $28.52( \pm 21.56)$, while that of the route running along the iterative route was $22.04( \pm 10.57)$ and 25.58 $( \pm 16.55)$. It indicated that the air route network in urban areas can greatly reduce the population exposure risk.

\section{Discussion and limitation}

\subsection{Air route planning environment}

Flight environment construction is the precondition of air route planning. Although UAV flight constraints are numerous, two categories can be distinguished by their effects: positive constraints and negative constraints. The positive constraint refers to elements that benefit the UAV flight (e.g., space above the green land). Conversely, the negative constraint refers to elements that restrict the UAV flight, including physical obstacles such as buildings and virtual obstacle space (e.g., electromagnetic zones). The positive and negative constraints are not opposite. Some elements may be attributable to any category according to the dividing principle. In the case of communication, it is a positive constraint from its positive influence; however, it can be a negative constraint when considering its weak-signal area (Xu et al., 2020). The minimum general element set proposed in this paper is only used as a reference, which varies with regional characteristics and can be expanded according to regional characteristics.

To utilize infrastructure and geographic information in an efficient way that allows classification, our study divided the UAV flying environment into the favorable space, obstacle space and communication space. When building the planning environment, the height range was delimited for each level of the air route based on the feature height count by the principle of zero risk of cross-collision on different levels of the air route. Different air route levels are at different heights, and there are isolation layers between each level. In the construction of low-altitude mobile communication environment, the UAV is used to measure the 
signal distribution of the single base station with a flight height greater than $30 \mathrm{~m}$ to ensure flight safety in the experiment. Therefore, the ground signal distribution is not included in the measured RSRP value, and the established channel modeling thus lacks the sheltering factor effect such as the near-ground buildings. Referring to the research conducted by Al-Hourani et al. (2018), the signal distribution of the base station was detected by aerial UAV measurement $(15-120 \mathrm{~m})$ and ground vehicle-mounted measurement $(5-15 \mathrm{~m})$. The measured RSRP value below 120 -m height at $1 \mathrm{~km}$ from the base station was between -110 $\mathrm{dBm}$ and $-90 \mathrm{dBm}$, while the measured value in this paper was between $-45 \mathrm{dBm}$ to -88 $\mathrm{dBm}$, indicating that there is great influence of ground buildings or other obstacles. Additionally, due to the lack of professional instruments and personnel, the interference or enhancement effect of signal superposition between multiple base stations is not considered. In the follow-up research, we propose to combine a large number of measured communication indicators and add vehicle-mounted signal measurement data along the road on the basis of the original UAV signal measurement, and expand the signal measurement height and area range to deepen the signal modeling research.

Furthermore, as UAV flight constraints are numerous, as well as in rich sources and at diverse scales, artificial extraction method is not suitable for application in large areas. It is necessary to construct a process to automatically or semi-automatically extract the sensitive geographical elements based on the UAV remote sensing images. This includes quickly acquiring and updating constraints of the large-range and high-precision air route network based on the UAV remote sensing network with multi-platforms and multi-sensors (Yan et al., 2019), exploring efficient extraction models and algorithms for each constraint combined with usual morphology, intelligent recognition and the latest deep learning methods to rapidly extract sensitive constraints (Xu et al., 2020).

\subsection{Air route network}

The iterative construction of the air route network proposed in this study is an innovative technology. Under the background of numerous constraints, constructing each step of the air route network can classifiably and efficiently utilize ground infrastructure and geographic information. Additionally, the iterative construction decomposes and then utilizes the constraints to facilitate the decomposition of the air route assessment and verification indicators, gradually achieving the goal of the air route as "flyable." Risk assessment results also indicated that the PERI of the air route network gradually reduces and stabilizes, especially from class I to class II with the iterative construction by making full use of the favorable space and avoiding obstacles. This greatly ensures the safety of UAV operations.

From the perspective of urban planning, most of the buildings may not exceed the building lines or boundary lines of roads (The Government of Tianjin, 2009). Therefore, the risk of collision between UAVs and buildings hardly occur in the class II air route network. However, this situation is not applicable inside the community. There are some class II air route segments that may pass through buildings (Figure 14c). Therefore, the class III air route network is constructed, aiming to avoid obstacles. The research uses the IACO algorithm to re-plan the conflicting flight segments, and then optimizes the path based on the cubic B-spline curve. 

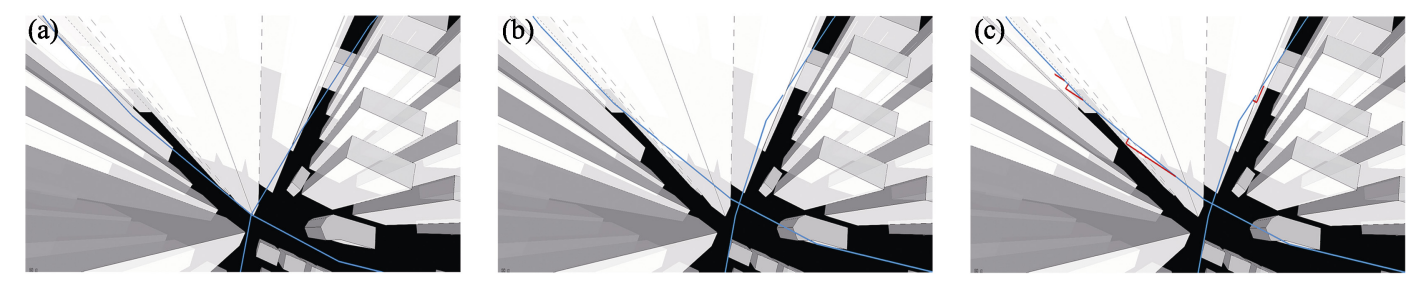

Figure 14 Air route network construction process (a. class I air route based on roads; b. class II air route based on favorable space; c. class III air route based on obstacle space; red line: re-planned air route segments)

There are many limitations in the iterative construction process of the air route network. JJXC is a plain area and a typical suburban area of the city, where buildings are mainly residential with low floors. Therefore, this research characterizes the strong regional features. In the class I air route network construction, height for each type of air route is based on the statistical height of ground objects and the distance and direction matrices in the construction of the class II air route are based on the actual survey of the relative positions between roads, and green land and rivers. The communication channel model and regional signal distribution involved in the construction of the class III air route have strong regional characteristics, which will cause certain restrictions on the promotion of research.

Secondly, this paper has not considered other attributes of low-altitude air routes of UAVs (the channel numbers and course, route spacing, etc.), and has not further designed the network connection (airspace connections between various types of air routes and UAV transition, etc.). In future research, we plan to explore the structural optimization of the low-altitude airspace, and to obtain attributes that conform to the regional characteristics and meet the dynamic performance of UAVs by resource quantitative calculation. This includes construction of a quantitative function between the route attribute and the low-altitude resource utilization by calculating the low-altitude resource utilization through the airspace throughput (Bulusu et al., 2018) and capacity (Salleh et al., 2018) indexes. The connection between different air route levels can be solved by integrating the BIM knowledge (Karachaliou et al., 2019) and subsequently designing the transition airspace in detail.

Finally, this study merely assesses the result from the theoretical view based on the population exposure risk index. The air route network is still far from being applicable in JJXC. Our team has been funded by the key deployment project of the Chinese Academy of Sciences - "Low-altitude UAV public air route planning and simulation verification system" project. With the support of the project, the simulated flight test and actual flight verification of the UAV in this study area will be conducted to ensure reasonability, high reliability, and practical applicability of the planned air route network.

\section{Conclusions}

Based on the theoretical system and technical pathway of the low-altitude UAV public air route network in urban areas proposed in earlier research, this paper further deepens and improves the research. It proposed a minimum general element set for constructing low-altitude UAV air route network and constructed a planning environment. This consisted of the favorable space, obstacle space, and communication space, by establishing a channel model and regional signal coverage of mobile base stations. It then iteratively constructed a low-altitude air route network that meets the UAV dynamic characteristics and assessed the 
network structure and safety by calculating the population exposure risk values. It forms a complete iterative construction pathway of regional air route network and obtains the preliminary feasible results through the actual case planning and evaluation. It provides a new idea for the coordination and integrated development of the ground road network and the UAV low-altitude air route network, and also provides a feasible way for the construction of the UAV logistics air route network based on the existing ground transportation infrastructure in local areas. The main conclusions are as follows:

Firstly, compared with free flights over urban areas, the risk of UAV operation is significantly reduced after the establishment of a low-altitude air route network, especially the secondary damage to vehicles along the road and the public in densely populated areas;

Secondly, the risk from class I to class III air route networks gradually reduced, indicating that each step of the iterative construction can effectively improve the safety of the air network, and that the stepwise iterative technology path is feasible.

The proposed methods and initial air routes network in typical demonstration areas can be used as a normative reference for the planning of national UAV low-altitude air routes in urban areas and further promoting the development of the construction technology of air route networks in low-altitude three-dimensional traffic network system.

\section{References}

3GPP, 2017. Study on enhanced LTE support for aerial vehicles (Release 15). https://www.3gpp.org/ftp/Specs/ archive/36_series/36.777/.

Air Traffic Management Research Institute (ATMRI), 2017. Framework for urban Traffic Management of Unmanned Aircraft Systems (uTM-UAS). DRONE ENABLE, ICAO Unmanned Aircraft Systems (UAS) Industry Symposium. Montreal, Canada.

Al-Hourani A, Gomez K, 2018. Modeling cellular-to-UAV path-loss for suburban environments. IEEE Wireless Communication Letter, 7(1): 82-85.

Alex F, 2018. Drones are everywhere. Get used to it. Time, 22(191): 24-25.

Amorim R, Nguyen H, Mogensen P et al., 2017. Radio channel modeling for UAV communication over cellular networks. IEEE Wireless Communication Letter, 6(4): 514-517.

Bahabry A, Wan X P, Ghazzai H et al., 2019. Low-altitude navigation for multi-rotor drones in urban areas. IEEE Access, 7: 87716-87731.

Bai L, Lu Z, Du X R et al., 2016. Rules and methods of UAV activities' aerial lanes design for (ultra) low airspace in regional areas. Advances in Earth Science, 31(11): 1197-1204. (in Chinese)

Bietlot, 2017. U-Space Blueprint. SESAR, Belgium, 978-92-9216-086-9. https:/www.sesarju.eu/u-space- blueprint.

Bulusu Vi, Sengupta R, Mueller E R et al., 2018. A throughput-based capacity metric for low-altitude airspace. Aviation Technology, Integration, and Operations Conference, Atlanta, Georgia, 1-9.

CAAC, 2009. Reference for route network planning methods. IB-TM-2009-009. (in Chinese)

CAAC, 2018. Test report of safe flights in low altitude for networked UAVs. http://www.caac.gov.cn/XXGK/ XXGK/GFXWJ/201811/t20181127_193186.html. (in Chinese)

CAAC, 2019. Guidelines on promoting the development of civil unmanned aviation (draft for comments). http://www.caac.gov.cn/HDJL/YJZJ/201905/t20190514_196175.html. (in Chinese)

Cape E, Dentist M, Mascarello L N et al., 2017. Regulation analysis and new concept for a cloud-based UAV supervision system in urban environment. Workshop on Research, Education and Development of Unmanned Aerial Systems (RED-UAS), Linkoping, Sweden, 90-95.

China Mobile, 2012. Acceptance specification on wireless engineering acceptance for TD-LTE system (1.0.0). QC-G-001-2012. (in Chinese)

Duan C P, Liu C, Wang Q, 2018. Application of B-spline theory to UAV flight track smoothing. Wireless Internet Technology, 15(3): 141-144. (in Chinese)

Feng D C, 2017. Construction of aircraft traffic management platform for low altitude security based on three dimensional digital aerial corridor. Computer Measurement \& Control, 25(12): 137-140, 161. (in Chinese) 
Feng D C, Qing H Y, Zeng Y et al., 2018. Research on city chart drawing in low altitude airspace based on three-dimensional visualization of aerial corridor. Journal of Electronic Measurement and Instrumentation, 32(4): 58-64. (in Chinese)

Feng D C, Yuan X H, 2016. Automatic construction of aerial corridor for navigation of unmanned aircraft systems in class G airspace using LiDAR. Airborne Intelligence, Surveillance, Reconnaissance (ISR) Systems and Applications XIII. Baltimore, Maryland, United States, 9828: 1-8.

Floreano D, Wood R J, 2015. Science, technology and the future of small autonomous drones. Nature, 521(7553): 460-466.

Karachaliou E, Georgiou E, Psaltis D et al., 2019. UAV for mapping historic buildings: From 3D modelling to BIM. ISPRS - International Archives of the Photogrammetry, Remote Sensing and Spatial Information Sciences, XLII-2/W9: 397-402.

Kopardekar P, Rios J, Prevot T et al., 2016. Unmanned Aircraft System Traffic Management (UTM) Concept of Operations. 16th AIAA Aviation Technology, Integration, and Operations Conference. Washington, D.C., $1-16$.

Liao X H, Xu C C, Yue H Y, 2018. Research on UAV low-altitude public air route planning based on geographic information. UAV, (2): 45-49. (in Chinese)

Lim C, Li B Y, Ng E M et al., 2019. Three-dimensional (3D) dynamic obstacle perception in a detect-and-avoid framework for unmanned aerial vehicles, 2019 International Conference on Unmanned Aircraft Systems (ICUAS), Atlanta, GA, USA, 988-996.

Lin X Q, Yajnanarayana V, Muruganathan S D et al., 2018. The Sky is not the limit: LTE for unmanned aerial vehicles. IEEE Communication Magazine, 56(4): 204-210.

Menouar H, Guvenc I, Akkaya K et al., 2017. UAV-enabled intelligent transportation systems for the smart city: Applications and challenges. IEEE Communication Magazine, 55(3): 22-28.

Primatesta S, Cuomo L S, Guglieri G et al., 2018. An innovative algorithm to estimate risk optimum path for unmanned aerial vehicles in urban environments. Transportation Research Procedia, 35: 44-53.

Quan Q, Li G, Bai Y Q, 2020. Low altitude UAV traffic management: An introductory overview and proposal. Acta Aeronautica et Astronautica Sinica, 41(1): 6-34. (in Chinese)

Salleh M F B M, Chi W C, Wang Z K et al., 2018. Preliminary concept of adaptive urban airspace management for unmanned aircraft operations. AIAA Information Systems: AIAA Infotech. Kissimmee, Florida, 1-12.

Schneider O, Kern S, Knabe F et al., 2014. METROPOLIS-Urban Airspace Design-Concept Design (D 2.2), https://homepage.tudelft.nl/7p97s/Metropolis/downloads/Metropolis_D2-2_Concept_Design_Report_v10.pdf.

Stolaroff J K, Samaras C, O’Neill E R et al., 2018. Energy use and life cycle greenhouse gas emissions of drones for commercial package delivery. Nature Communication, 9(1): 1-13.

Tan D Y, Chi W C, Salleh M F B M et al., 2017. Study on impact of separation distance to traffic management for small UAS operations in urban environment. International Conference on Transdisciplinary Engineering. IOS Press, 5: 39-45.

Tan Q Y, Wang Z K, Ong Y S et al., 2019. Evolutionary optimization-based mission planning for UAS traffic management (UTM). 2019. International Conference on Unmanned Aircraft Systems (ICUAS). Atlanta, GA, USA, 944-950.

The Government of Tianjin, 2009. Technical regulations on urban planning and management in Tianjin, China. (in Chinese)

Wang C H J, Tan S K, Ting L K J et al., 2018. Impact of sensors on collision risk prediction for non-cooperative traffic in terminal airspace. International Conference on Unmanned Aircraft Systems (ICUAS), Dallas, TX, USA, 177-185.

Wang W, Chen X W, 2017. Transportation Planning. 2nd ed. Beijing: China Communication Press Co., Ltd.

Xu C C, Liao X H, Yue H Y et al., 2019a. 3-D path-searching for UAVs using geographical spatial information. IEEE International Geoscience and Remote Sensing Symposium. Yokohama, Japan, 947-950.

Xu C C, Liao X H, Yue H Y et al., 2019b. Construction of a UAV low-altitude public air route based on an improved ant colony algorithm. Journal of Geo-information Science, 21(4): 570-579. (in Chinese)

Xu C C, Ye H P, Yue H Y et al., 2020. Research on iterative construction of UAV low-altitude air route network in urbanization region: Theoretical system and technical roadmap. Acta Geographica Sinica, 75(5): 917-930. (in Chinese)

Yan L, Liao X H, Zhou C H et al., 2019. The impact of UAV remote sensing technology on the industrial development of China: A review. Journal of Geo-information Science, 21(4): 476-495. (in Chinese)

Zhu L, Yin D, Shen L C et al., 2015. Research on urban application-oriented route planning of UAV based on mobile communication network. 4th International Conference on Computer Science and Network Technology (ICCSNT 2015), Harbin, China, 1562-1570. 